Research, Society and Development, v. 9, n. 9, e77996530, 2020

(CC BY 4.0) | ISSN 2525-3409 | DOI: http://dx.doi.org/10.33448/rsd-v9i9.6530

Fatores que influenciam na qualidade da carne de frango: uma breve revisão

Factors that influence the quality of chicken meat: a brief review

Factores que influyen en la calidad de la carne de pollo: una breve revisión

Recebido: 09/07/2020 | Revisado: 29/07/2020 | Aceito: 04/08/2020 | Publicado: 12/08/2020

\title{
Mailson Gonçalves Gregório
}

ORCID: https://orcid.org/ 0000-0002-6960-7973

Universidade Federal de Campina Grande, Brasil

E-mail: gregoriomailson@gmail.com

Alícia Nayana dos Santos Lima de Brito

ORCID: https://orcid.org/ 0000-0003-3572-9726

Universidade Federal de Campina Grande, Brasil

E-mail: anslbrito@outlook.com

Airton Gonçalves de Oliveira

ORCID: https://orcid.org/ 0000-0001-7150-0123

Universidade Federal de Campina Grande, Brasil

E-mail: airtonifce@yahoo.com.br

Nágela Maria Henrique Mascarenhas

ORCID: https://orcid.org/ 0000-0001-9059-3695

Universidade Federal de Campina Grande, Brasil

E-mail: eng.nagelamaria@gmail.com

Francisco Jean da Silva Paiva

ORCID: https://orcid.org/000-0001-7603-4782

Universidade Federal de Campina Grande, Brasil

E-mail: je.an_93@hotmail.com

Moisés Sesion de Medeiros Neto

ORCID: http://orcid.org/0000-0002-9536-0214

Universidade Federal de Campina Grande, Brasil

E-mail: moisesion@live.com

Luis Paulo Firmino Romão da Silva

ORCID: https://orcid.org/ 0000-0002-4816-1116

Universidade Federal de Campina Grande, Brasil

E-mail: luispfrs@hotmail.com 


\section{Semirames do Nascimento Silva}

ORCID: https://orcid.org/ 0000-0001-7252-6026

Universidade Federal de Campina Grande, Brasil

E-mail: semirames.agroecologia@gmail.com

\section{Resumo}

O Brasil possui um dos maiores sistemas de produção de frango de corte mundial, sendo responsável por apresentar o maior fluxo de exportação da carne de frango e a segunda maior taxa de produção do planeta, com excelente qualidade nutricional. Objetivou-se revisar de forma simples e sistemática pesquisas relacionadas aos fatores que influenciam na qualidade final da carne de frango. A qualidade da carne de frango produzida no Brasil tem total relação com as boas práticas adotadas nas diferentes fases do sistema produção, como bem-estar do animal, manejo nutricional de forma correta, uma vez que as rações oferecidas para as aves são compostas por ótimos nutrientes, como também as práticas de adotadas nas etapas do préabate, tais como transporte, tempo de descanso, pendura, imobilização e atordoamento do animal. Além disso, o Brasil possui sérios serviços de fiscalizações no sistema agropecuária, garantindo dessa forma a sanidade das aves, um dos resultados positivos do serviços de fiscalizações é ausência da influenza aviária, também conhecida como gripe do frango, gripe aviária ou menos comumente como resfriado das aves ou do frango, é uma doença infecciosa aguda altamente contagiosa descrita em diversas espécies animais inclusive, em humanos, causado pelo vírus da influenza tipo A.

Palavras-chave: Manejo nutricional; Bem-estar animal; Saúde animal; PSE; Qualidade da carne.

\footnotetext{
Abstract

Brazil has one of the largest chicken production systems in the world, being responsible for presenting the largest flow of chicken meat exports and the second highest production rate on the planet, with excellent nutritional quality. Objective: To review a simple and systematic form of research related to the factors that influence the final quality of chicken meat. The quality of chicken meat in Brazil is totally related to good practices adopted at different stages of the production system, such as animal welfare, nutritional management in a correct way, since the relationships offered to birds are composed of excellent nutrients, as well as practices adopted in the pre-reduction stages, such as transportation, rest time, suspension, immobilization and stunning animals. In addition, Brazil has inspection services in the
} 
agricultural system, thus adopting the health of birds, one of the positive results in inspection services is the lack of avian influenza, also known as chicken flu, avian flu or less commonly as a cold. of poultry or chicken, is a highly infectious acute infectious disease, which occurs in several species of animals, including humans, caused by type A viruses.

Keywords: Nutritional management; Animal welfare; Animal health; PSE; Meat quality.

\section{Resumen}

Brasil tiene uno de los sistemas de producción de pollo más grandes del mundo, siendo responsable de presentar el mayor flujo de exportaciones de carne de pollo y la segunda tasa de producción más alta del planeta, con excelente calidad nutricional. Objetivo: revisar una forma simple y sistemática de investigación relacionada con los factores que influyen en la calidad final de la carne de pollo. La calidad de la carne de pollo en Brasil está totalmente relacionada con las buenas prácticas adoptadas en diferentes etapas del sistema de producción, como el bienestar animal, el manejo nutricional de manera correcta, ya que las relaciones que se ofrecen a las aves están compuestas de excelentes nutrientes, así como prácticas adoptadas en las etapas previas a la reducción, como transporte, tiempo de descanso, suspensión, inmovilización y aturdimiento de animales. Además, Brasil cuenta con servicios de inspección en el sistema agrícola, adoptando así la salud de las aves, uno de los resultados positivos en los servicios de inspección es la falta de influenza aviar, también conocida como gripe aviar, gripe aviar o menos comúnmente como un resfriado. de aves de corral o pollo, es una enfermedad infecciosa aguda altamente infecciosa, que ocurre en varias especies de animales, incluidos los humanos, causada por virus tipo A.

Palabras clave: Manejo nutricional; Bienestar de los animales; Salud animal; PSE; Calidad de la carne.

\section{Introdução}

A pecuária de corte apresenta destaque dentro das diretrizes sociais e econômicas no Brasil, com elevada variedade de raças, sistema de produção otimizado, taxa de produtividade e situação sanitária, com base nas características de cada região geográfica e do mercado consumidor (Cinquini Filho et al., 2011; Ferraz \& Felício, 2010).

O sistema de produção de frango de corte, em operação industrial é um dos segmentos que mais da agropecuária com melhores resultados. A proteína oriunda da carne do frango é a mais consumida em todo território brasileiro e a segunda mais consumida no planeta, esse 
elevado consumo tem relação com a qualidade nutricional da carne, valor do produto final e versatilidade durante o preparo, além de não apresentar nenhuma aversão religiosa, com isso, aumenta o público consumidor (Belusso \& Hespanhol, 2010). Por outro lado, as pessoas estão mais atentas com o bem-estar das aves nos diferentes sistemas de criação e/ou manejo das aves. O consumidor anseia que a produção em escala industrial não seja tão abusiva, em que os animais tenham uma ótima condição de saúde e comportamento natural (Nazareno et al., 2011).

De acordo com os obtidos da Associação Brasileira de Proteína Animal (ABPA), no ano de 2017 o sistema de produção brasileiro de frango de corte foi de 13,5 milhões de toneladas, dessa forma, o Brasil continua apresentando a maior taxa de exportação mundial e o segundo maior produtor de carne de frango, seguido dos Estados Unidos. Em 2017 cerca de $66,9 \%$ da produção da carne do frango foram destinadas ao consumo interno e $33,1 \%$ da produção foi submetido ao sistema de exportação. No Brasil, o consumo per capito foi em torno de 42,07 Kg/ano e o escoamento de exportação foi de 4,3 milhões de toneladas, sendo destinado para mais de 150 países, atuando em torno de $40 \%$ no mercado internacional da carne de frango. A avicultura de escala industrial brasileira é responsável por empregar mais de 5 milhões de pessoas e correspondendo a 1,5\% do Produto Interno Bruto (PIB) brasileiro. Este segmento é composto por vários produtores e empresas tecnológicas que beneficiam a carne de frango (Abpa, 2018).

A qualidade final da carne é uma das principais preocupações nos últimos anos, principalmente pelo os consumidores mais exigentes. Sendo assim, existe uma relação direta com as práticas adotadas no pré-abate, desde da propriedade, meio de transporte, ou na cadeia frigorifica. Neste contexto, várias estratégias visando programas de qualidade da carne devem evidenciar a segurança dos produtos, bem como a qualidade nutritiva e as características sensoriais, promovendo tratos visando a produção de forma sustentável e promoção do bemestar das pessoas e dos animais, firmando os desejos do consumido e a rentabilidade do produtor rural, sem causar danos ao meio ambiente (Barbosa Filho \& Silva, 2004; Guarnieri et al., 2002; Molento, 2005; Oliveira et al., 2008).

Diante do exposto, o presente trabalho teve como objetivo revisar de forma simples e sistemática pesquisas relacionadas aos fatores influenciam na qualidade da carne de frango industrial. 


\section{Metodologia}

O presente estudo, trate-se de uma revisão exploratória, de natureza qualitativa (Pereira et al., 2018), através de pesquisas bibliográficas com relação aos fatores que influenciam na qualidade da carne de frango. Os artigos utilizados para a confecção desta revisão foram retirados de bases indexados: CAPES, PUBMED, SCIELO, SCOPUS, SCIENCE DIRECT, ELSEVIER, sendo recorte temporal das últimas duas décadas

\section{Resultados e Discussão}

\section{Avicultura de corte brasileira}

O sistema de produção de frangos de corte no Brasil tem vantagens competitivas devido ao rápido ciclo produtivo, ao fato de ter a possibilidade de uma estrutura organizacional verticalizada e de ser uma proteína de baixo custo, o que atrai consumidores de diferentes classes sociais (Reck \& Schultz, 2016). Ela é caracterizada, como mostram, pelo uso de sistemas modernos de planejamento, organização, coordenação, técnicas gerenciais e, principalmente, pela incorporação de novas tecnologias que resultam em um constante crescimento da produção (Reck \& Schultz, 2016, Espínola, 2012). Destaca que a incorporação das novas tecnologias possibilitou a melhoria nos sistemas de produção e controle, a redução dos custos de energia e matéria-prima, a diversificação da matriz energética e do mix de produtos industrializados oferecidos. Os grandes avanços da pesquisa no desenvolvimento de novas tecnologias no setor da avicultura converteram o Brasil em um dos maiores produtores e exportadores de carne de frango mundiais (Espínola, 2012).

No caso da cadeia produtiva de frangos de corte, até quatro décadas atrás, ela estava centrada em pequenas propriedades rurais e a sua produção era comercializada de forma direta para pequenos açougues (Santos, 2014). A partir dos anos 1970 ocorrem mudanças tecnológicas e na estrutura produtiva, destacando-se a redução do tempo de engorda das aves de corte; um grande avanço na seleção de linhagens; a intensificação do uso de rações balanceadas; o uso de equipamentos industriais de última geração e novas técnicas de manejo das aves, resultando em significativos ganhos de produtividade (Espínola, 2012).

A avicultura brasileira é uma atividade importante na geração de renda, seja de maneira direta ou indireta, influenciando de forma positiva a economia nacional. Sendo assim, esse segmento é formado por dezena de milhares de empresas e/ou empresários que 
distribuem a carne do frango para o mercado consumidor (União Brasileira de Avicultura, 2012).

Um dos diferenciais da carne de frango brasileira é qualidade, uma vez que as legislações especificas proibiram o uso de hormônios na produção de aves e, além disso, o sistema de produção é submetido com frequência fiscalizações de forma rigorosa, com finalidade de controlar os resíduos de medicamentos, em que está situado no Plano de Controle de Resíduos e Contaminantes (PNRC) do Ministério da Agricultura, Pecuária e Abastecimento (MAPA). Outro aspecto importe para a qualidade da carne é que o Brasil não tem registos em casos gripes (Influenza Aviária), patologia de alto risco, esse resultado é em função dos rígidos controles traçados o pelo Plano Nacional de Influenza Aviária, também criado pelo MAPA e do trabalho sério que as empresas do setor aviário desempenham. (União Brasileira De Avicultura, 2012).

\section{Bem-estar animal}

O bem-estar animal possui várias definições básicas, porém um aumento consensual no que se refere a real definição, devendo incluir três elementos: estado comportamental e/ou emocional do animal, desempenho funcional biológico e capacidade de evidenciar padrões de normalidade (Manteca et al., 2009).

Com finalidade de identificar os principais problemas do bem-estar dos animais, o Conselho de Bem-estar de Animais de Produção - Farm Animal Welfare Council (FAWC, 2009) desenvolveu as 5 liberdades dos animais, ou seja, representando os estados ideais. Para que o animal seja considerado em ótimo estado de bem-estar, se o mesmo estiver em pleno gozo de sua condição de saúde, seja relacionado a conforto, nutrição, seguro e expressar seu comportamento natural, sem apresentar dores, medo e estresse. O bem-estar dos animais, visa a prevenção de doenças e tratamento médico, ambiente adequado, gestão correta, manejo nutricional, manejo cuidadoso e abate humanitário (Bonamigo et al., 2012; Hötzel \& Machado Filho, 2004).

Um dos fatores importantes na manutenção da qualidade do bem-estar das aves é a condição climática, podendo influenciar na qualidade final da carne do frango de corte. $\mathrm{O}$ clima brasileiro é tropical por estar situado entre dos trópicos de câncer e capricórnio (Köppen \& Geiger, 1928), por ser um país de proporções continentais, é dividido em regiões, sendo que boa parte das regiões brasileiras possui temperaturas e umidade do ar elevadas durante grande parte do ano. Os parâmetros climáticos favorecem de forma significativa o desconforto 
por apresentar sensação térmica desagradável para as aves. Neste contexto, as condições climáticas que as aves são submetidas é uma das principais preocupações da avicultura brasileira (Silva \& Vieira, 2010).

As condições ambientais para promover o conforto térmico dos frangos são aquelas que permite que a ave apresente todo seu desempenho genético durante a produção. Os de sistemas de criação mais sofisticados são complemente automatizados, controlando a temperatura e a umidade relativa do ar. No entanto, esta forma de produção possui custos elevados de implantação e manutenção, o que faz que muitos produtores a criar os animais em ambientes convencionais, em que se tem maior dificuldade em promover conforto térmico para os frangos (Furlan \& Macari, 2008).

\section{Manejo nutricional}

O manejo nutricional das aves muda em função das diferentes fases do desenvolvimento, ou seja, sendo necessário que haja fornecimento de rações que supra a necessidade nutricional, visando aumento no peso e na qualidade final da carcaça. Dessa forma, no mercado existe vários tipos de rações com diferentes níveis de carboidratos, proteínas, lipídios, minerais e vitaminas (Oliveira, 2019).

Para que a nutrição das aves ocorra de maneira correta, é necessário ter conhecimento técnico em relação a cada nutriente envolvido nas rações, tais como aminoácidos, minerais, vitaminas, ácidos graxos e água. Os nutrientes utilizados em menores concentração são são conhecidos como de micro-ingredientes e são adicionados na ração das aves por meio de misturas pré-estabelecidas, porém mesmo sendo em pequenas quantidades, esses nutrientes possuem funções vitais no desenvolvimento das aves e na qualidade final da carne dos frangos (Premix) (Bellaver, 2003).

O manejo nutricional quando ocorre em níveis de ingestão de nutrientes digestíveis, pode afetar de maneira significativa na composição nutricional na carcaça. O maior efeito na carcaça já observado foi na concentração de gordura. A alimentação com menor teor de gordura na fase de engorda, resultará na redução de gordura da carcaça do frango, de maneira semelhante ocorre quando há uma alimentação com elevada concentração de gordura, resultando em uma carne mais "gorda" (Moletta et al., 2014). Dietas baseadas em alto teor de energia deve ser ofertadas, visando melhor rendimento na eficiência de produção (Prado, 2010). 


\section{Manejo no pré-abate}

Nos últimos anos é crescente a preocupação dos consumidores com maneira que os animais são criados, transportados e abatidos, sendo assim, um dos desafios para as agroindústrias desenvolver um novo paradigma tecnológico, visando a melhoria da carcaça, dos produtos de origem animal, além da manutenção ética (Ludtke et al., 2012; Ludtke et al., 2010a).

Os princípios essenciais que devem ser observados visando atender o bem-estar nas etapas do pré-abate são: manejo adequado e instalações que promova a redução do estresse dos frangos, equipe técnica e totalmente capacitada, equipamentos modernos e apropriados e eficiência no método de insensibilização, ocasionando de modo imediata a perda de consciência e sensibilidade dos frangos, sem ocorrer o surgimento de dor durante a sangria (Ludtke et al., 2010b).

As etapas no pré-abate inclui apanha, jejum, transporte, tempo de descanso, pendura, imobilização e atordoamento do animal exercendo influência significativa na reserva de glicogênio muscular, sendo o principal "combustível” no desenvolvimento de todas as reações bioquímicas que ocorrem no, transporte, tempo de descanso, pendura, imobilização e atordoamento do animal, determinado a qualidade final da carne. $\mathrm{O}$ estresse sofrido pelas as aves pode afetar as propriedades sensórias e funcionais das proteínas (Aguiar, 2006).

\section{Comportamento bioquímico rigor mortis}

A oscilação fisiológica ocasionado pelas as altas temperaturas e umidade do ar, no processo do abate, têm efeito direto nas reservas de glicogênio. (Brossi et al., 2009). O glicogênio presente no músculo tem uma função primária na manutenção e/ou conservação da carne, rendendo assim diferentes níveis de qualidade. Os problemas mais comuns são a carne pálida, mole e exsudativa (PSE) e a carne dura, escura e seca (DFD), sendo que a PSE está relacionada com a redução rápida do $\mathrm{pH}$ no post mortem. Quando a temperatura corporal esta elevada e baixo $\mathrm{pH}$ promove desnaturação das proteínas, tornado a carne mais pálida e diminuindo a capacidade de retenção de água (CRA) sendo esse o resultado do manejo quando ocorre de forma errada, principalmente quando há indícios mal tratos e situações estressantes a que os animais são submetidos, provocando o rigor mais acelerado (Takahashi, 2007). 
Research, Society and Development, v. 9, n. 9, e77996530, 2020

(CC BY 4.0) | ISSN 2525-3409 | DOI: http://dx.doi.org/10.33448/rsd-v9i9.6530

Este fenômeno e a junção do baixo $\mathrm{pH}$, em grande maioria menor que 5,8 e com a elevada temperatura muscular acima de $35^{\circ} \mathrm{C}$, rendendo na desnaturação das proteínas, e por consequência desse comportamento, a carne se torna mais macia, sem apresentar nenhum tipo de aderência e descolorida, com manutenção das propriedades funcionais. Isso acontece devido há uma rápida transformação metabólica do glicogênio em ácido láctico atingindo o pH final antes do resfriamento completo da carcaça, tornando a carne pálida (Takahashi, 2007).

Estudos comprovam a existência da carne PSE não apenas de carnes suínas e de peru. Os frangos possuem alta suscetibilidade ao estresse, sendo assim, é possível ocorrer desnaturação das proteínas durante o processo bioquímico de transformação do músculo em carne, com o surgimento de carne PSE. Evidências mostras que a condição da carne PSE em frangos é de origem genética. Porém, até o presente momento não se conhece claramente se possui relação com a linhagens de frango (Olivo \& Shimokomaki, 2006).

\section{Composição química da carne do frango}

A composição química da carne do frango apresenta uma variação em relação a concentração de água (umidade), proteína e gordura. No geral, a carne é composta por $60 \%$ a $80 \%$ de água e de $15 \%$ a $25 \%$ de proteínas. O teor de lipídeos no músculo das aves é totalmente variável, sofrendo influência da composição da dieta, sexo, idade e ambiente de criação.

O teor de lipídeos das aves pode ser alterado com facilidade, uma vez que a composição lipídica da ração influencia diretamente da qualidade e no tipo de lipídeo presente na carne do frango.

Para os lipídios, os valores presentes na literatura variam de 1,5 a $5,3 \%$, respectivamente na carne do peito, e valores mais elevados é encontrado na carne da coxa. A carne de frango possui vitaminas, principalmente do complexo $\mathrm{B}$, minerais, com destaque para ferro, vários nutrientes (Bragagnolo, 2001).

\section{Considerações Finais}

As políticas de fiscalização dos órgãos competentes são de suma importância para manutenção da saúde e do bem-estar dos animais durante toda cadeia de produção/criação dos animais. A qualidade final da carne de frango, assim como boa parte das carnes de outros 
Research, Society and Development, v. 9, n. 9, e77996530, 2020

(CC BY 4.0) | ISSN 2525-3409 | DOI: http://dx.doi.org/10.33448/rsd-v9i9.6530

animais depende totalmente de todas as etapas que antecedem o produto final, tais como melhoramento genético, manejo nutricional, bem-estar e sanidade animal.

Problemas relacionados pelo o manejo inadequado no manejo do pré-abate, em especial ao transporte, insensibilização (atordoamento) e o abate, são fatores que atuam de forma direta na qualidade carne, podendo apresentar carcaças com danos físicos (hematomas), redução no peso e estresse, promovendo as características organoléticas e nutricionais.

Trabalhos futuros podem analisar influência da genética das aves, sexo, idade e diferentes práticas em relação ao manejo nutricional, visando obter uma carne de frango com ótima qualidade química/ nutricional.

\section{Referências}

Abpa. Associação Brasileira Proteína Animal. Mercado Mundial. 2018. Recuperado de http://abpa-br.com.br/storage/files/relatorio-anual-2018.pdf

Aguiar, A. P. S. (2006). Opinião do consumidor e qualidade da carne de frangos criados em diferentes sistemas de produção, 2006, 70p. Dissertação (Mestrado em Ciências) - Escola Superior de Agricultura “Luiz de Queiroz”, Universidade de São Paulo.

Barbosa Filho, J. A. D., \& Silva, I. J. O. (2004). Abate humanitário: ponto fundamental do bem-estar animal. Revista Nacional da Carne, 328, 36-44.

Bellaver, C. (2003). Sistemas de produção de frangos de corte-nutrição e alimentação. Recuperado de http://sistemasdeproducao.cnptia.embrapa.br

Belusso, D., \& Hespanhol, A. N. (2010). A evolução da avivultura industrial brasileira e sues efeitos territorias. Revista Percurso, 2(1), 25-51.

Bonamigo, A., Bonamigo, C. B. S. S., \& Molento, C. F. M. (2012). Atribuições da carne de frango relevantes ao consumidor: foco no bem-estar animal. Revista Brasileira de Zootecnia, 41, 1044-1050. 
Bragagnolo, N. (2001). Aspectos comparativos entre carnes segundo a composição de ácidos graxos e teor de colesterol.In: II Conferência Internacional Virtual sobre Qualidade de Carne Suína.

Brossi, C., Castillo, C. J. C., Amazonas, E. A., Menten, J. F. M. (2009). Heat stress during the pre-slaughter on broiler chicken. Ciência Rura, 39(4), 1284-1293.

Cinquini Filho, J., Moura, M. S., Carreon, R. S., \& Pirtouscheg, A. (2011). Economic performance of the production system creates and fattening in beef cattle farm Rosário Ituiutaba-MG. Pubvet: publicações em medicina veterinaria e Zootecnia, 5, 1056

Espíndola, C. J. Trajetórias do progresso técnico na cadeia produtiva de carne de frango do Brasil (2012). Revista Geosul, 27(53), 89-113.

Ferraz, J. B. S., \& Felício, P. E. (2010). Production systems - An example from Brazil. Meat Science, 84: 238-243.

Guarnieri, P. (2002). Bem estar animal e qualidade da carne. Uma exigência dos consumidores. Revista Nacional da Carne 26, 36-44.

Hötzel, M. J., \& Machado Filho, L. C. P. (2004). Bem-estar animal na agricultura do século XXI. Revista de Etologia, 6, 3-15.

Köppen, W., \& Geiger, R. (1928). Klimate der Erde. Gotha: Verlag Justus Perthes. Wall-map $150 \mathrm{~cm} \times 200 \mathrm{~cm}$.

Ludtke, C. B., Ciocca, J. R. P., Dandin, T., Barbalho, P. C. \& Vilela, J. A. (2010b). Abate humanitário de aves. WSPA Brasil, Rio de Janeiro.

Ludtke, C. B., Dalla Costa, O. A., Roça, R. d. O., Silveira, E. T. F., Athayde, N. B., Araújo, A. P., Azambuja, N. C. (2012). Bem-estar animal no manejo pré-abate e a influência na qualidade da carne suína e nos parâmetros fisilógicos do estresse. Ciência Rural, 42(3),532537. 
Ludtke, C. B., Silveira, E. T. F., Bertoloni, W., Andrade, J. C., Buzelli, M. L. T., Bressa, L. R. \& Soares, G. J. D. (2010a). Bem-estar e qualidade de carne de suínos submetidos a diferentes técnicas de manejo pré-abate. Revista Brasileira de Saúde e Produção Animal, 11(1),231-241.

Manteca, X., Velarde, A., \& Jones, B. (2009). Animal welfare components. In: F. Smulders \& B. Algers (eds.) Welfare of production animals: assessment and management of risks, 61-77, Wageningen.

Molento, C. F. M. (2005). Bem-estar e produção animal: Aspectos econômicos - Revisão. Archives of Veterinary Science, 10, 1-11.

Moletta, J. L., Torrecilhas, J. A., \& Ornaghi, M. G. (2014). Feedlot performance of bulls and steers fed on three levels of concentrate in the diets. Acta Scientiarum. Animal Sciences, 36: 323-328.

Nazareno, A. C., Pandorfi, H., Guiselini, C., Vigoderis, R. B., \& Pedrosa, E. M. R. (2011). Bem-estar na produção de frango de corte em diferentes sistemas de criação. Engenharia Agrícola, 31(1), 13-22.

Oliveira, C. B., Bortoli, E. C., \& Barcellos, J. O. J. (2008). Diferenciação por qualidade da carne bovina: a ótica do bem-estar animal. Ciência Rural, 38, 2092-2096.

Oliveira, M. E. M (2019). Manejo de frangos de corte: do incubatório ao abate. Trabalho de conclusão de curso (Medicina veterinária/unidade acadêmica de caranhus).

Olivo, R., Shimokomaki, M., Franco, B. D. M., Terra, N. N. (2006). Carne PSE em aves. In: (Ed.). Atualidades em ciência e tecnologia de carnes. São Paulo, SP: Varela, 2006, cap. 9, 95113.

Pereira, A. S., Shitsuka, D. M., Parreira, F. J., \& Shitsuka, R. (2018). Metodologia da pesquisa científica. [e-book]. Santa Maria. Ed. UAB/NTE/UFSM. Recuperado de https://repositorio.ufsm.br/bitstream/handle/1/15824/Lic_Computacao_MetodologiaPesquisaCientifica.pdf?sequence $=1$. 
Prado, I. N. (2010). Produção de bovinos de corte e qualidade da carne. Eduem, Maringá, Paraná, Brasil.

Reck, A. B., \& Schultz, G. (2016). Aplicação da metodologia multicritério de apoio à decisão no relacionamento interorganizacional na cadeia da avicultura de corte. Rev. Econ. Sociol. Rural, 54(4),709-728.

Santos, G. R. (2014). Cadeias Agroindustriais e Avicultura no Brasil: organização produtiva e upgrading por cooperativas. serie documentos del reporte anual 2014, recursos naturales y desarrollo. red sudamericana de economía aplicada.

Silva, I., \& Vieira, F. (2010). Ambiência animal e as perdas produtivas no manejo pré-abate: o caso da avicultura de corte brasileira. Archivos de Zootecnia, 59,113-131.

Takahashi, S. E. (2007). Influência da genética e das práticas de manejo sobre a ocorrência de carne PSE em frangos de corte. Tese (Dissertação em Zootecnia) Universidade Estadual Paulista Júlio de Mesquita Filho, UNESP, Brasil.

União Brasileira De Avicultura. Relatório anual UBABEF (2012). São Paulo, 2012. Recuperado de https://abef.com.br/ubabef/exibenoticiaubabef.php?notcodigo=3293

Vieira, S. L. (2014). Considerações sobre as características de qualidade de carne de frango e fatores que podem afetá-la. In: Simpósio Brasil Sul De Avicultura, 15, 61-72.

\section{Porcentagem de contribuição de cada autor no manuscrito}

Mailson Gonçalves Gregório - 12,5\%

Alícia Nayana dos Santos Lima de Brito - 12,5\%

Airton Gonçalves de Oliveira - 12,5\%

Nágela Maria Henrique Mascarenhas - 12,5\%

Francisco Jean da Silva Paiva - 12,5\%

Moisés Sesion de Medeiros Neto - 12,5\%

Luis Paulo Firmino Romão da Silva - 12,5\%

Semirames do Nascimento Silva $-12,5 \%$ 